\title{
Research into Individual Factors Affecting Safety within Airport Subsidiaries
}

\author{
Jin-Hwan Bae and Jin-Woo Park *(D) \\ School of Business, Korea Aerospace University, Goyang-si 10540, Korea; jennings1@naver.com \\ * Correspondence: jwpark@kau.ac.kr; Tel.: +82-2-300-0354
}

check for updates

Citation: Bae, J.-H.; Park, J.-W. Research into Individual Factors Affecting Safety within Airport Subsidiaries. Sustainability 2021, 13, 5219. https://doi.org/10.3390/ su13095219

Academic Editors: Paola Di Mascio and Marc A. Rosen

Received: 9 March 2021

Accepted: 5 May 2021

Published: 7 May 2021

Publisher's Note: MDPI stays neutral with regard to jurisdictional claims in published maps and institutional affiliations.

Copyright: (C) 2021 by the authors. Licensee MDPI, Basel, Switzerland. This article is an open access article distributed under the terms and conditions of the Creative Commons Attribution (CC BY) license (https:/ / creativecommons.org/licenses/by/ $4.0 /)$.

\begin{abstract}
This study's purpose is to demonstrate that, from the point of view of employees in subsidiary companies, individual factors, notably attitude towards risk, cognitive bias, knowledge and experience, and risk perception, have generated unsafe behavior and unsafe conditions and have undermined safety performance through risk tolerance. The data underpinning this research were derived from a survey of employees working in subsidiary companies within the vicinity of Incheon International Airport. In total, 409 questionnaires were analyzed using network structural equation modeling (SEM), a methodology representing, estimating, and testing relationships. This analysis has demonstrated within the bounds of statistical significance (a) that the attitudes towards risk, knowledge and experience, and cognitive bias affect risk tolerance and (b) that risk tolerance influences unsafe behavior, unsafe conditions, and safety performance. This research is the first to apply the accident causal model to the airport industry, and its conclusions can be used for accident prevention within Incheon International Airport's subsidiaries.
\end{abstract}

Keywords: risk tolerance; attitude toward risk; risk perception; knowledge and experience; cognitive bias; unsafe behavior; unsafe conditions; safety performance

\section{Introduction}

Research into human error within the airline industry commenced in the 1940s when pilots recognized that it was an important safety element in their selection criteria. Between the 1970s and 1990s, these human factors became prominent, and during the new millennium, human errors have received extensive attention [1]. Safety is now recognized as a systematic perspective, embodying both human and organizational factors, in a bid to eliminate human error from the airline industry [2]. The International Civil Aviation Organization (ICAO) has undertaken innovative research into human factors within the aviation industry. These research results have been received by aviation industries, but they have been restricted in their adoption to aviation safety regulations, ramp safety, and tower control safety. Since 1981, the safety and health of airport workers in the Republic of Korea have been protected under the Occupational Safety and Health Act, which is applicable to all workers [3]. Nevertheless, there has been no research based on the individual care of airport workers to inform a specific aviation safety policy and law.

In Korea, airport industries have played an important role in the development of the economy, especially in generating employment within the vicinity of Incheon International Airport (IIA). Among the 76,800 workers at IIA, those at subsidiary companies accounted for more than 10,000 workers. These workers are engaged in a variety of activities ranging from maintenance (building, communications, computing, and cleaning), security and services for airport workers, passengers and cargo terminals, firefighting, and first aid for emergency to guidance within the airport. Since the opening of IIA in 2001, there have been formal safety education courses adhering to the Occupational Safety and Health Act [4]. In the case of subsidiaries in the IIA, safety management activities have been mainly executed by a top-down method using "service level agreements" that include 
clauses governing safety management and imposing investigations of subsidiaries when safety agreements have been violated. The declaration system, covering facility safety, disaster safety, employee safety, and threats to safety, was introduced in The Safety Report of Incheon Airport, but there have been no cases that have progressed safety management using both a bottom-up method and a focus on individual factors.

Many accident causal models have been suggested by scholars for over a century. However, typical and representative accident causal models have become obscure. It has been simply too difficult to undertake systematic research using them [5]. In particular, the difference between the accident causal model and practical statistical analysis has made empirical studies difficult.

This study counters to this trend by using the accident causal model to tackle safety within the airport industry. Since 2000s, the model has been used mainly for studying safety within the construction industry. Nevertheless, the model is used here in an aviation context to consider three overlooked issues: (1) how have individual factors-attitudes toward risk, risk perception, knowledge and experience, and cognitive bias-affected risk tolerance; (2) how has risk tolerance affected unsafe behavior, unsafe conditions, and safety performance; and (3) how are unsafe behavior, unsafe conditions, and safety performance related to each other?

These issues are addressed by initially establishing the theoretical background of accident causal models. Then, the methodology is established from a literature review to tackle the three nominated issues. This leads to an empirical analysis of the three issues. Finally, conclusions are drawn from this study before considering its implications, limitations, and scope for further research. Thus, this study can contribute to saving airport workers lives and decreasing accident rates by suggesting improvements to individual safety. Additionally, it can be used for its data on individual factors affecting safety in and around the airport.

\section{Theoretical Background}

An accident is an unplanned inconvenient event that causes undesirable consequences, and the occurrence of such an event may bring about unrecognized or unaddressed risks [6]. Risk as defined by ISO 31000 is the "effect of uncertainty on objectives" [7], and most researchers have focused on factors that reduce injury incidence and avoid accidents. Heinrich et al. [8] defined accident prevention as "an directly integrated program and coordinated activity about unsafe behavior and the state of unsafe equipment, based on knowledge, attitude and ability", and finally, they created "Domino theory", the origin of the accident causation model.

The accident causation model starts with two questions: Why do accidents happen? How do accidents happen? The model's purpose is to reveal accident procedures and consequences and to prevent accidents through clear analyses about their cause [5] This model has been applied predominantly in the construction industries [9]. The factors affecting unsafe behavior and unsafe conditions within the construction arena have been researched by many scholars, but unsafe behavior and unsafe conditions are mostly proven to be caused by the factors of organization, control, and management.

For instance, Heinrich et al. [10] estimated that $88 \%$ of accidents are caused directly by unsafe behavior and that $10 \%$ of accidents are caused by unsafe conditions. Through Domino theory, personal faults or carelessness have been seen as negative characteristics of human personality that have led to unsafe behavior and conditions that result in an unsafe act and finally cause an accident. This interpretation has faced criticism because the research overlooked the control and management of human behavior involved as the cause of accidents. Thus, Petersen [11], Weaver [12], Bird, and Loftus [13] proposed using the accident causal model focused on both safety control and management.

In response, Heinrich et al. [8] developed an accident theory based on human factors. While they stated that human error has been the main cause of accidents, other factors should be taken into account such as anxiety; pressure; fatigue; and an inadequate work 
environment occasioned by dust, light, noise, and smell. Additionally, a lack of knowledge and intentional risk-taking have brought about unsafe behavior that has led to accidents. These human errors have been divided by Wiegmann and Shappell [14] using the Human Factor Analysis and Classification System (HFACS) into unsafe acts, preconditions, unsafe supervision, and organizational influence. This procedure has resulted in the causes of accidents being considered not only by individual factors but also by external factors, notably management, control, and organization. Since this study's initial application to aviation accidents involving the US Navy and Marines, the analysis has been extended to accidents involving aviation control and maintenance. Subsequently, an accident causation model focusing on risk tolerance was developed by Wang et al. [15] by drawing upon the existing accident causation model to confirm factors and paths affecting the risk tolerance of construction workers. This has led to a modified accident causal model, which established a causal relationship between work characteristics, safety management, knowledge and experience, and subjective perceptions affecting risk tolerance. Then, Banus et al. [16] synthesized several studies on construction safety that led to a new model, which incorporated both individual factors, such as attitude toward risk, cognitive bias, and risk perception, and organizational factors, notably work conditions and safety climate, affecting risk-taking behavior. These are considered in turn.

Attitude is the psychological characteristic used to evaluate specific entities by likability [17]. Risk has two components: a risk arising from the possibility of an accident and a risk due to an incorrect judgement [18]. Risk in this study stems from the possibility of accidents. Attitude towards risk is defined as either the positive or negative evaluation about working, and it can be referred to as risk neutral, risk aversion, or risk seeking [15]. Thus, attitude towards risk is an essential factor of risk tolerance [19]. This attitude towards risk contributes to traffic safety in safety science, especially predictions of unsafe actions by drivers [20].

Risk perception can be defined as subjective judgement about frequency and seriousness toward specific dangers [21]. Risk perception is the cognitive ability to determine whether a behavior is dangerous and if it relies on the values, interests, and knowledge of human beings [22]. Sensitivity towards potential danger is deeply related to the safety perception of workers because it can prevent workers from unnecessary injuries and can remind them of the existence of danger. The workers who are sensitive to potential dangers have an active cautious attitude when recognizing and handling dangers and when facing safety hazards [15], which lead to reduced risk tolerance. While identifying the cause of the worker's unsafe behavior, Kim et al. [23] reflected upon the worker's risk perception. Ultimately, the worker's unsafe behavior can be classified into either intended behavior or unintended behavior. The intended behavior is when the worker recognizes a dangerous situation and then reacts to it using a cognitive process. Unintended behavior is when an action is performed without awareness of a dangerous situation. If these circumstances are underestimated or overestimated, they lead to negative risk perception [24]. This has led to Hunter [25] mentioning that inaccurate risk perception leads to unsafe behavior by allowing the pilot to overlook or misinterpret external cues when it requires immediate and effective decisions to avoid threats in aviation.

Knowledge consists of safety knowledge, working knowledge, and professional knowledge. When workers with rich experiences and expert knowledge are faced with safety problems of risk tolerance, safety knowledge becomes more rational and objective. Sometimes, workers fail to recognize dangers, caused by a lack of information, experience, and proper training, and it leads to other workers and themselves being exposed to danger [26]. Expert knowledge and experience towards safety not only provide qualitative expert skills but also establish restrictions about workers' workloads, with an understanding of possible losses and seriousness relating to risk tolerance. The workers who have rich experience and expert knowledge become more rational and reduce risk tolerance when facing safety hazards [15]. 
Cognitive bias includes overconfidence, illusions of control, and belief [27]. These items were mentioned by Montibeller and Von Winterfeldt [28] in their study of how cognitive bias can affect risk tolerance and behavioral decision-making about violating acceptable general principles. Furthermore, Simon et al. [27] recognized that people can evoke an error of judgement due to excessive belief and control. Indeed, a person who has a high level of cognitive bias, probably has fewer experiences with negative accidents [16]. Additionally, Lichtenstein et al. [29] concluded that people tend to overestimate their abilities and to underestimate risk when preventing or controlling accidents.

Risk tolerance has been defined by various scholars. For example, Irwin and Charles [30] defined financial risk-taking as "An action of willing to bear the uncertainty of outcome despite the possibility of an identifiable negative outcome". Based on this definition, risk tolerance has been defined as a willingness to accept the risk perceived by workers who, having recognized potential risks, decide how to proceed based on whether it is safe or unsafe [26]. Furthermore, Kemp [31] has classified risk tolerance into subjective risk-taking (acceptable) and objective risk-taking (tolerable). Subjective risk tolerance (acceptable) is a risk that people are willing to take. Following the definition of the Securities and Exchange Commission (SEC) about risk tolerance in the financial field, risk tolerance is defined as the ability and willingness to lose a portion of all investments in order to gain greater potential profits [21]. Additionally, Hunter [25] has defined risk tolerance as readily accepting the amount of risk taken on by pilots who pursue their own goal during flights, such as arriving at the airport as fast as possible. Indeed, Jonah [32] compared risk-taking to reckless driving and found that young drivers frequently take more risks because their risk perception towards danger is small. Thus, objective risk tolerance can be defined as the amount of uncertain risks that should be endured. In comprehending risk-taking towards workers in the construction industry, Banus et al. [16] emphasized the important role that construction companies and related organizations should play in managing construction accidents and in controlling safety activities.

Unsafe behavior has been identified by Mitropoulos et al. [33] as an inappropriate response to a situation such as not following safety work procedures or taking incorrect actions in a predicably dangerous situation. Indeed, unsafe behavior by workers is perceived as both a direct and general reason for accidents [34]. Not only is unsafe behavior a key factor in the occurrence of accidents [35], but also, according to Choudhry and Fang [36], performance pressure is a one of the causes of unsafe behavior. Furthermore, Seo [37] stated that perceived production pressure, including heavy workload, assigned work speed, and time pressure, has been the cause of accidents and unsafe behavior. Nevertheless, an uncertain amount of risk should be endured as objective risk acceptance.

Unsafe conditions, according to Abdelhamid et al. [9], are violations of current safety standards within a workplace or work location, physical layout, tools, equipment, or instructions. Unsafe conditions have been recognized as a key factor in all accident causal models. The primary causes of unsafe conditions include management behavior, incomplete behavior of workers and coworkers, and natural events not related to people. Additionally, Zhang and $\mathrm{Xu}$ [38] added unsafe conditions in the production environment in terms of the environment, which includes ventilation, lighting, temperature, humidity, confusion, and geographic environments. Furthermore, unsafe conditions of equipment can be a hidden danger due to incomplete installation or faults in its deployment and operation.

Safety performance was defined by Rowlinson [39] as being the purpose of creating safety programs at construction sites to prevent inappropriate behavior causing accidents and to detect and report problems. Safety programs have been designed as a preparatory procedure for improving safety performance at construction sites [40]; these involve the preparation of safety working environments for workers to reduce accidents and injuries, and the creation of a safety culture within the organization [41]. If workers are aware of their unsafe conditions, they should stop working until risk assessments are finished and the unsafe conditions are corrected [9]. Ultimately, these remedial activities are part of safety performance. This is reflected in Aksorn et al. [42], which divided the critical success 
factors affecting safety program performance into worker involvement, safety prevention, control system, safety arrangement, and management commitment. In this research, safety performance is regarded as relevant to both workers and the duty of management. Indeed, Nicole et al. [43] stated that projects should be developed to prevent accidents rather than to lower their incidence. Ultimately, unsafe behavior and unsafe conditions are the main causes of construction accidents that are due mainly to the incorrect use of equipment or improper safety management. Additionally, after accidents occur, they may adversely affect safety performance [15].

Having elaborated on the key factors, this research is organized as a two-step process. First, the accident causation mechanism suggested by Heinrich et al. [10] and a modified causation model proposed by Wang et al. [15] and Banus et al. [16] for the construction industry are applied to the airport industry. Secondly, the researchers added safety related features drawn from previous research into the construction safety and a variety of studies into safety fields to identify a range of variables for inclusion in a modified accident causal model; these variables include attitude toward risk risk perception, knowledge and experience, and cognitive bias on human factors, unsafe behavior, unsafe conditions, and safety performance. Thus, the researchers developed a detailed causal model regarding individual factors affecting safety at work at and round the airport. This led to an examination of how individual factors affect risk tolerance and the effects of risk perception on unsafe behavior, the effects of risk tolerance effect on unsafe behavior, the effects of unsafe behavior on unsafe conditions, and safety performance in the development of a causal relationship between them.

\section{Methodology}

Based on a review of the preceding research, the following model suggests that individual factors-such as attitude toward risk, risk perception, knowledge and experience, and cognitive bias-have an effect on risk tolerance, that risk perception has an effect on unsafe behavior, that risk tolerance has an effect on unsafe behavior, that unsafe behavior has an effect on unsafe conditions and safety performance, and that unsafe conditions have an effect on safety performance as a causal relationship. The hypothesis established in this research is shown below, with the research model shown in Figure 1.

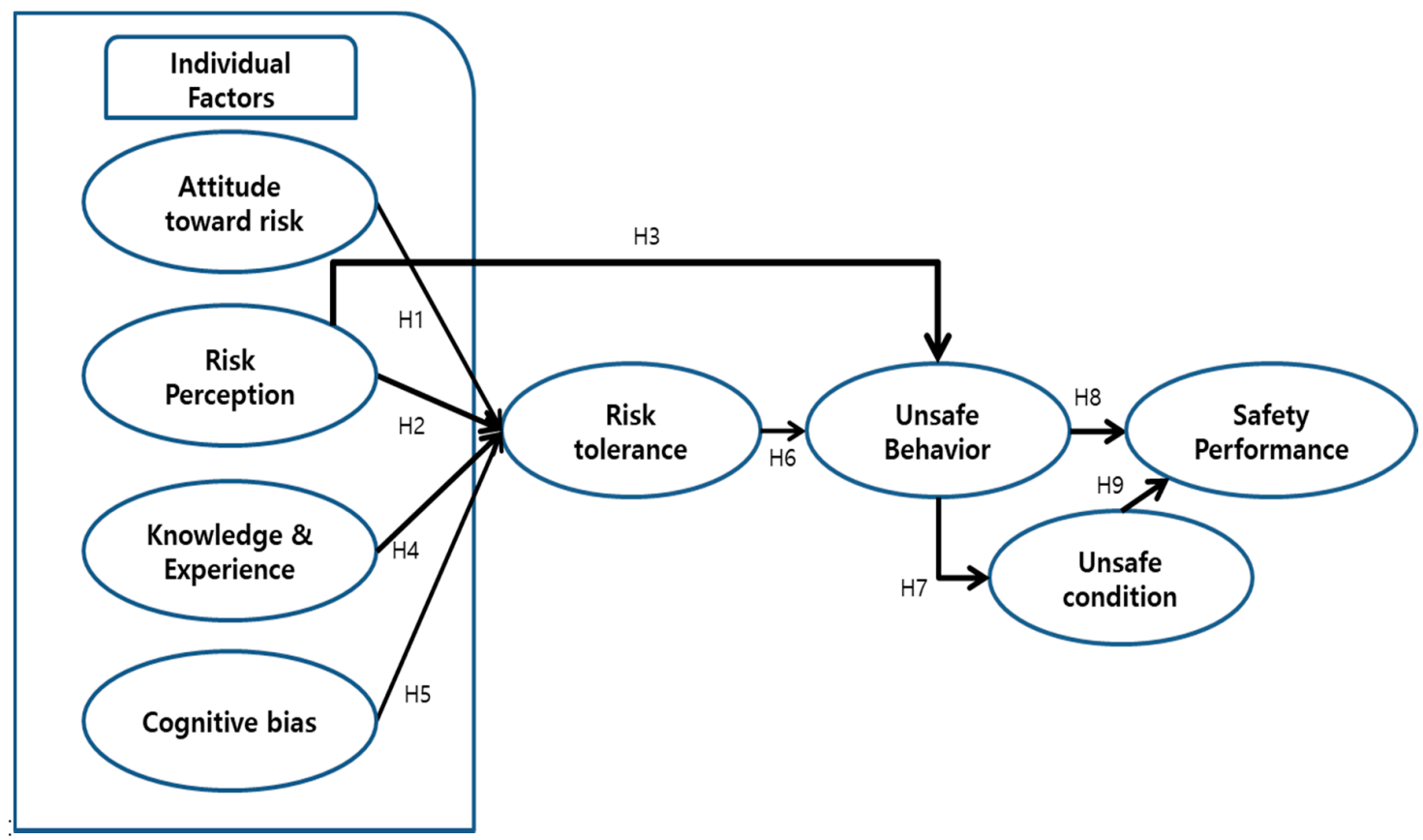

Figure 1. Conceptual framework. 
Hypothesis 1 (H1). Attitudes toward risk have an impact on risk tolerance.

Hypothesis 2 (H2). Risk perception has an impact on risk tolerance.

Hypothesis 3 (H3). Risk perception has an impact on unsafe behavior.

Hypothesis 4 (H4). Knowledge and experience have an impact on risk tolerance.

Hypothesis 5 (H5). Cognitive bias has an impact on risk tolerance.

Hypothesis 6 (H6). Risk tolerance has an impact on unsafe behavior.

Hypothesis 7 (H7). Unsafe behavior has an impact on unsafe conditions.

Hypothesis 8 (H8). Unsafe behavior has an impact on safety performance.

Hypothesis 9 (H9). Unsafe conditions have an impact on safety performance.

The present survey is based on measurement items from previous research to show the newly modified causation model with regard to safety in the airport. For preparation of the questionnaire, related factors were derived from previous studies and some terminologies were modified to suit this study. The questionnaires used in this research were based upon a review of the literature. The review was used to conduct a preliminary investigation and to develop a questionnaire suitable for this particular topic. A five-point Likert scale was used in the original questionnaire, which comprised a total 26 questions-two were for attitudes toward risk, three were for risk perception, five were for knowledge and experience, two were for cognitive bias, five were for risk tolerance, three were for unsafe behavior, three were for unsafe conditions, and three were for safety performance. The researchers reviewed the questionnaire with three aviation experts in the safety field. These experts found that some questions were unsuitable for probing the arena of airport safety, which resulted in some questions being changed. After reviewing all questions, the researchers distributed the questionnaires to managers of subsidiaries within in the vicinity of IIA engaged in security, firefighting, airport maintenance, and cargo terminal maintenance. The total number questionnaires delivered was 455 (200 to security staff, 167 to firefighters, 40 to airport maintenance staff, 42 to cargo terminal maintenance, and 6 others for face-to-face surveys). Between 16 March and 20 March 2020, 444 questionnaires were returned. Of these, 409 were selected for the final data analysis. The contents of the questionnaire and their related studies are shown in Table 1.

Table 1. Measurement items.

\begin{tabular}{crc}
\hline Construct & Item & Related Studies \\
\hline $\begin{array}{c}\text { Attitude } \\
\text { Toward Risk }\end{array}$ & $\begin{array}{c}\text { Sometimes, I take a risk to finish work. } \\
\text { Taking a risk to finish work is a good idea. }\end{array}$ & Banus et al. [16] \\
$\begin{array}{c}\text { Risk } \\
\text { Perception }\end{array}$ & $\begin{array}{c}\text { It is dangerous to keep working even though I am tired and fatigued. } \\
\text { It is dangerous to practice unsafe behavior merely because it is convenient. } \\
\text { It is dangerous not to wear safety equipment. }\end{array}$ & Banus et al. [16] \\
\hline
\end{tabular}

I know safe methods for conducting a task.

I know how to react when an emergency occurs.

Knowledge and experience situations. 
Table 1. Cont.

\begin{tabular}{|c|c|c|}
\hline Construct & Item & Related Studies \\
\hline \multirow{4}{*}{ Risk tolerance } & $\begin{array}{l}\text { When you work, there are circumstances for not wearing safety equipment. } \\
\text { There is personal safety equipment that is not appropriate for use. }\end{array}$ & Wang et al. [15] \\
\hline & There are cases where risks should be taken to finish work quickly. & $\begin{array}{l}\text { Fogarty and Shaw [44] } \\
\text { Sandhaland et al. [45] }\end{array}$ \\
\hline & There is a lack of time to follow safety rules and procedures. & $\begin{array}{l}\text { Fogarty and Shaw [44]; } \\
\text { Mohammadfam and } \\
\text { Ghasemi [46] }\end{array}$ \\
\hline & To get the job done, safety procedures can be omitted. & Sandhaland et al. [45] \\
\hline $\begin{array}{l}\text { Unsafe } \\
\text { Behavior }\end{array}$ & $\begin{array}{c}\text { There are sometimes wrong responses towards an emergency. } \\
\text { There are inadequate directions for safety. } \\
\text { There is a lack of knowledge about safety activities. }\end{array}$ & Zhou et al. [47] \\
\hline $\begin{array}{l}\text { Unsafe } \\
\text { Conditions }\end{array}$ & $\begin{array}{c}\text { There are unnecessary working guidance rules about safety activities. } \\
\text { It is not necessary for safety rules to be applied strictly. } \\
\text { Working environments are unsafe and poor. }\end{array}$ & Zhang et al. [38] \\
\hline $\begin{array}{l}\text { Safety } \\
\text { Performance }\end{array}$ & $\begin{array}{c}\text { There should be high rates of participation in safety and health activities by } \\
\text { employees. } \\
\text { There are incentives for participating in safety activities. } \\
\text { There are budgets and finances for safety activities. }\end{array}$ & Nicole et al. [43] \\
\hline
\end{tabular}

The researchers conducted a frequency analysis to identify sample features; then, they conducted a confirmatory factor analysis to identify the internal validity of measured models; and finally, they drew results using path analysis. Table 2 shows that, among the 409 valid responses, $348(85.1 \%)$ respondents were male and $61(14.9 \%)$ were female. In terms of age distribution, there were 145 people in their $30 \mathrm{~s}(35.5 \%), 119$ people in their $40 \mathrm{~s}$ $(29.1 \%), 92$ people in their 20s $(22.5 \%), 35$ people in their $50 \mathrm{~s}(8.6 \%)$, and 17 people in their $60 \mathrm{~s}(4.2 \%)$, and those in their $30-40 \mathrm{~s}$ accounted for more than $60 \%$ of the total. In terms of the level of education, 150 respondents (36.7\%) were university graduates, 146 respondents $(35.7 \%)$ were college graduates, and 103 respondents were high school graduate. Thus, almost $74 \%$ of the total numbers were educated beyond the college graduate level.

Table 2. Demographic features.

\begin{tabular}{|c|c|c|c|}
\hline \multicolumn{2}{|c|}{ Division } & \multirow{2}{*}{$\begin{array}{c}\text { Frequency } \\
348\end{array}$} & \multirow{2}{*}{$\begin{array}{c}\text { Percentage } \\
85.1 \%\end{array}$} \\
\hline Gender & Male & & \\
\hline entes & Female & 61 & $14.9 \%$ \\
\hline \multirow{6}{*}{ Age } & Less than 10 & 1 & $0.2 \%$ \\
\hline & $20-29$ & 92 & $22.5 \%$ \\
\hline & $30-39$ & 145 & $35.5 \%$ \\
\hline & $40-49$ & 119 & $29.1 \%$ \\
\hline & $50-59$ & 35 & $8.6 \%$ \\
\hline & $60-69$ & 17 & $4.2 \%$ \\
\hline \multirow{5}{*}{ Level of education } & High school & 103 & $25.2 \%$ \\
\hline & College & 146 & $35.7 \%$ \\
\hline & University & 150 & $36.7 \%$ \\
\hline & Graduate university & 5 & $1.2 \%$ \\
\hline & No response & 5 & $1.2 \%$ \\
\hline
\end{tabular}




\section{Empirical Analysis}

The path analysis was conducted to verify variable validity after the confirmatory factor analysis was conducted. Additionally, one item on the questionnaire-safety performance-was eliminated because "There should be high rates of participation in safety and safety activities by employees" did not show internal validity. After reanalysis, there was one item-attitude toward risk, represented by "Taking a risk to finish work is a good idea" - that recorded an SMC score of 0.302 , but it was retained. If this value was eliminated, it would have evoked a negative effect on the whole research model used in this research, so it was important to keep this question in structural equation modeling (SEM) to represent, estimate, and test relationships to specifically explain the variables of attitude toward risk.

The SMC value was used to determine how well each concept was explained rather than the explanatory ability of the model as a whole. When confirmatory factor analysis was performed, the questionnaire items with low explanatory abilities were removed by referring to the SMC value, but it was not referred to in fitting the model. Although an SMC of the measured variable can be low, the fit to the model may be high. Conversely, the SMC may be high, but the fit to the model may be low. This can have a negative effect on the overall research model diagram if a single item is removed from the questionnaire simply because the SMC is low [48]. Thus, this research eliminated only one item: safety performance ("There should be high rates of participation in safety and health activities by employees"). The other questionnaire item with a lower SMC value regarding attitude toward risk, "Taking a risk to finish work is a good idea", was retained. The latter item has an intensive feasibility of more than 0.5 as an SRC value.

The concept of Average Variance Extracted (AVE) used to gauge convergent validity was suggested by Fornell and Larcker [49]. It is validated by at least a reading of more than 0.5 of AVE related to the observation variables. Construct reliability was used to obtain intensive feasibility, and it measures internal consistency. Indeed, Anderson and Gerbing [50] explained that construct reliability must be more than 0.7 to guarantee internal consistency and to explain intensive feasibility well. The variables of this research model show a greater than 0.7 construct reliability and 0.5 AVE; therefore, it is proven that this research model is validated in Table 3.

Table 3. Results of the confirmatory factor analysis.

\begin{tabular}{|c|c|c|c|c|c|c|c|}
\hline Latent Variable & MeasurementVariable & SRC & SMC & AVE & Construct Reliability & C.R & $p$-Value \\
\hline Attitude & AT1 & 0.957 & 0.916 & 0.58 & 0.72 & 5.459 & $* * *$ \\
\hline Toward Risk & AT2 & 0.550 & 0.302 & 0.58 & 0.72 & - & - \\
\hline \multirow{3}{*}{$\begin{array}{c}\text { Risk } \\
\text { Perception }\end{array}$} & $\mathrm{RP} 1$ & 0.718 & 0.515 & 0.75 & 0.96 & 13.411 & $* * *$ \\
\hline & $\mathrm{RP} 2$ & 0.865 & 0.748 & 0.75 & 0.96 & 14.586 & $* * *$ \\
\hline & RP3 & 0.745 & 0.554 & 0.75 & 0.96 & - & - \\
\hline \multirow{5}{*}{$\begin{array}{l}\text { Knowledge and } \\
\text { Experience }\end{array}$} & NE1 & 0.809 & 0.654 & 0.77 & 0.97 & 19.515 & $* * *$ \\
\hline & NE2 & 0.842 & 0.709 & 0.77 & 0.97 & 20.751 & $* * *$ \\
\hline & NE3 & 0.676 & 0.457 & 0.77 & 0.97 & 15.118 & $* * *$ \\
\hline & NE4 & 0.851 & 0.724 & 0.77 & 0.97 & - & - \\
\hline & NE5 & 0.790 & 0.623 & 0.77 & 0.97 & 18.830 & $* * *$ \\
\hline \multirow{2}{*}{ Cognitive Bias } & CB1 & 0.873 & 0.762 & 0.74 & 0.90 & - & - \\
\hline & CB2 & 0.748 & 0.559 & 0.74 & 0.90 & 12.939 & $* * *$ \\
\hline \multirow{5}{*}{ Risk Tolerance } & RT1 & 0.692 & 0.479 & 0.62 & 0.79 & 15.936 & $* * *$ \\
\hline & RT2 & 0.640 & 0.410 & 0.62 & 0.79 & 14.322 & $* * *$ \\
\hline & RT3 & 0.857 & 0.735 & 0.62 & 0.79 & 22.193 & $* * *$ \\
\hline & RT4 & 0.800 & 0.640 & 0.62 & 0.79 & 19.824 & $* * *$ \\
\hline & RT5 & 0.864 & 0.747 & 0.62 & 0.79 & - & - \\
\hline \multirow{3}{*}{$\begin{array}{l}\text { Unsafe } \\
\text { Behavior }\end{array}$} & UB1 & 0.793 & 0.629 & 0.73 & 0.88 & - & - \\
\hline & UB2 & 0.881 & 0.775 & 0.73 & 0.88 & 20.017 & $* * *$ \\
\hline & UB3 & 0.804 & 0.646 & 0.73 & 0.88 & 17.816 & $* * *$ \\
\hline
\end{tabular}


Table 3. Cont

\begin{tabular}{|c|c|c|c|c|c|c|c|}
\hline Latent Variable & MeasurementVariable & SRC & SMC & AVE & Construct Reliability & C.R & $p$-Value \\
\hline \multirow{3}{*}{$\begin{array}{c}\text { Unsafe } \\
\text { Conditions }\end{array}$} & UC1 & 0.821 & 0.674 & 0.63 & 0.79 & - & - \\
\hline & $\mathrm{UC2}$ & 0.872 & 0.760 & 0.63 & 0.79 & 19.716 & $* * *$ \\
\hline & UC3 & 0.656 & 0.430 & 0.63 & 0.79 & 13.894 & $* * *$ \\
\hline Safety & SP2 & 0.700 & 0.489 & 0.69 & 0.84 & 7.224 & $* * *$ \\
\hline Performance & SP3 & 0.926 & 0.858 & 0.69 & 0.84 & - & - \\
\hline
\end{tabular}

The model was fitted using a confirmatory factor analysis, and it shows $x^{2}=559.175$, $\mathrm{RMR}=0.036, \mathrm{CMIN} / \mathrm{DF}=2.264, \mathrm{GFI}=0.903, \mathrm{AGFI}=0.873$, and RMSEA $=0.056$. Except the low AGFI, all indices were appropriate so this research model can be considered an empirical model with a high level of accuracy. Finally, a goodness-of-fit analysis was performed for the structural equation model, and the results from verifying the goodnessof-fit of the model are shown in Table 4 . The conclusion of path analysis about this model shows $x^{2}=616.106, \mathrm{RMR}=0.042, \mathrm{CMIN} / \mathrm{DF}=2.370, \mathrm{GFI}=0.894, \mathrm{AGFI}=0.867$, and RMSEA $=0.058$, and even though GFI and AGFI are slightly lower, there is no problem in satisfying the acceptance level of the goodness of fit.

Table 4. Model fits using a goodness of fit analysis.

\begin{tabular}{|c|c|c|}
\hline \multicolumn{2}{|c|}{ Division } & \multirow{2}{*}{$\begin{array}{c}\text { Results } \\
2.370\end{array}$} \\
\hline \multirow{5}{*}{ Absolute fit index } & CMIN/DF & \\
\hline & RMR & 0.042 \\
\hline & GFI & 0.894 \\
\hline & AGFI & 0.867 \\
\hline & RMSEA & 0.058 \\
\hline \multirow{4}{*}{ Incremental fit index } & NFI & 0.897 \\
\hline & TLI & 0.928 \\
\hline & CFI & 0.937 \\
\hline & IFI & 0.938 \\
\hline \multirow{3}{*}{ Parsimony fit index } & PGFI & 0.715 \\
\hline & PNFI & 0.778 \\
\hline & PCFI & 0.812 \\
\hline
\end{tabular}

As individual factors affecting safety work in the airport, attitude toward risk (hypothesis 1 ) had a statistically positive effect: $S R C=0.381, C R=6.717, p<0.001$. This means that the attitude toward risk has a big influence on risk tolerance (Table 5). Hypotheses 2 and 3 were rejected because of a low significance level. This means that these hypotheses are not supported in this research model. Hypothesis 4 had a statistically negative effect: $\mathrm{SRC}=-0.295, \mathrm{CR}=-4.403, p<0.001$, meaning that knowledge and experience affect risk tolerance. Hypothesis 5 had a statistically negative effect: $\mathrm{SRC}=-0.176, \mathrm{CR}=-2.440$, $p<0.015$. This means that, if cognitive bias is higher, risk tolerance decreases marginally and proves that self-confidence with cognitive bias can help prevent accidents from risk tolerance. Hypothesis 6 had a very large statistically positive effect: $S R C=0.866, C R=16.047$, $p<0.001$. Hypothesis 7 also had a large statistically positive effect: $\mathrm{SRC}=0.877, \mathrm{CR}=12.482$, $p<0.001$. Hypothesis 8 was rejected because of its low significance level. Hypothesis 9 had a statistically negative effect: $\mathrm{SRC}=-0.305, \mathrm{CR}=-1.970, p<0.049$. This indicates that, when unsafe conditions were higher, safety performance became weak. The analysis also showed that attitude toward risk, knowledge and experience, and cognitive bias influence 
safety performance through unsafe behavior and unsafe conditions. This means that the hypotheses of this research proved that the new, modified causation model can be applied to various industries. This research proved for the first time that individual factors affect safety in the airport, which leads to step forward regarding scientific methods for assessing safety not only in the field of aviation but also in various industries.

Table 5. Results of hypothesis testing.

\begin{tabular}{lccccc}
\hline & Path & SRC & C.R & $p$-Value & Decision \\
\hline H1 & Attitude toward risk $\rightarrow$ Risk tolerance & 0.381 & 6.717 & & $* * *$ \\
H2 & Risk perception $\rightarrow$ Risk tolerance & 0.017 & 0.288 & 0.773 & Supported supported \\
H3 & Risk perception $\rightarrow$ Unsafe behavior & 0.039 & 1.037 & 0.300 & Not supported \\
H4 & Knowledge and experience $\rightarrow$ Risk tolerance & -0.295 & -4.403 & $* * *$ & Supported \\
H5 & Cognitive Bias $\rightarrow$ Risk tolerance & -0.176 & -2.440 & 0.015 & Supported \\
H6 & Risk tolerance $\rightarrow$ Unsafe behavior & 0.866 & 16.047 & $* * *$ & Supported \\
H7 & Unsafe behavior $\rightarrow$ Unsafe conditions & 0.877 & 12.482 & $* * *$ & Supported \\
H8 & Unsafe behavior $\rightarrow$ Safety performance & -0.027 & -0.194 & 0.846 & Not supported \\
H9 & Unsafe conditions $\rightarrow$ Safety performance & -0.305 & -1.970 & 0.049 & Supported \\
\hline
\end{tabular}

Note: ${ }^{* * *} p<0.001$; SRC: Standardized Regression Weights

\section{Conclusions and Implication}

This research assessed the effect of individual factors on the safety of workers at IIA. Using causal modeling, the research analyzes how individual factors affect risk tolerance, unsafe behavior, unsafe conditions, and safety performance. The initial finding is that risk tolerance has a strong influence on unsafe behavior. In turn, unsafe behavior affects unsafe conditions. The outcome is that risk tolerance leads to unsafe behavior, which in turn creates further unsafe conditions, creating a vicious cycle. Second, the hypothesis that risk perception affects risk tolerance and unsafe behavior negatively was rejected. This finding suggests that there is a simple risk perception, but this perception does not directly affect risk tolerance and unsafe behavior. Third, the hypothesis that knowledge and experience affects risk tolerance has been validated within a statistical level of significance. Fourth, the hypothesis of cognitive bias affecting risk tolerance returned a negative SRC value of -0.173 . Finally, positive statistical significance was found in the hypothesis of attitude toward risk affecting risk tolerance.

Based on these research results, the following four implications stemming from this research can be presented. First, in previous research, the Accident Causation Mechanism proposed by Heinrich [10] and the modified causal relationship model proposed by Wang et al. [15] were applied to the safety of airport workers for the first time. Second, there was a new discovery about the effect that cognitive bias has on risk tolerance. The effect of cognitive bias on risk tolerance was supported negatively. The researchers concluded that excessive self-confidence and beliefs in preventing accidents through safety activities and enough work experience affects risk tolerance negatively; therefore, self-confidence and cognitive bias can somewhat help prevent accidents caused by risk tolerance. Third, this research is the first investigation to extend the construction safety model to the field of airport safety. Significantly, the scope of research on individual factors that was restricted to aviation, airport passengers, and logistics services has now been expanded to incorporate airport safety. In practical terms, airport workers should refrain from risk tolerance behavior for quick task completion and managers should desist from actions that encourage workers to take risks in order to achieve work goals within a limited time frame. In terms of social policy support, safety activities such as work training, and improving knowledge and experience on safety matters should be continued because accidents can be prevented through training and education. In terms of system and environmental improvement, investments in the safety field through incentives and budgets are necessary to improve unsafe conditions, such as changing unnecessary work guidelines, applying safety regulations clearly, and improving poor working conditions. Ultimately, risk tolerance as a causal 
model has a very large impact on unsafe behavior and unsafe conditions; therefore, policy support is needed to reduce risk tolerance. Fourth, this research not only can provide information about individual factors affecting safety within airport subsidiaries to airport officials but can also be applied to risk assessment through the identification of potential risks of individual factors within the risk management process of ISO 31000 [50]. Therefore, this research can provide basic information about individual factors affecting safety within various working groups to decision makers, who would then use the developed accident causation model.

Nevertheless, this research on individual factors affecting safety within the airport environment has its limitations. First, this research focused on employees in subsidiary companies, so the sample groups may not reflect other areas of safety in the airport such as ground handling, aircraft handling, and passenger handling. Therefore, future research should be conducted using surveys from employees working in these areas. Second, thus far, the primary focus of research has been on individual factors related to the innate characters and features of personnel rather than on organizational factors such as organizational cultures. If these factors are added, different research conclusions may emerge, particularly in relation to risk perception, which can be changed through control and management by organizational factors. Despite these limitations, this research has proven for the first time that individual factors affect safety in the airport and this research can be used beyond safety around airports to examine safety in other industries.

Looking ahead, two areas worthy of further research are how policy activities and safety-related incentives from budget support may modify individual and organizational safety and how organizational and control factors shape worker perception of safety at work. Furthermore, this research could be applied to risk management systems using ISO 31000; therefore, it is essential to study individual and organizational factors affecting risk management in various industries using this developed accident causation model. If research on both individual and organizational factors influencing safety at work are conducted, they can be applied to our risk management system in airports, for which the findings can be used by airport safety officers to establish clearer policy directions for airport safety, which would reduce the loss of life occasioned by accidents within and around airports.

Author Contributions: Conceptualization, J.-H.B. and J.-W.P.; data curation J.-H.B.; formal analysis, J.-H.B.; investigation, J.-H.B.; methodology, J.-H.B. and J.-W.P.; supervision of the research, J.-W.P.; data collection and analysis, J.-H.B.; writing original draft, J.-H.B.; writing-review \& editing J.-H.B. and J.-W.P. Both authors have read and agreed to the published version of the manuscript.

Funding: This research received no external funding.

Informed Consent Statement: Not applicable.

Data Availability Statement: Not applicable.

Conflicts of Interest: The authors declare no conflict of interest.

\section{References}

1. Hubbard, S.M.; Lopp, D. An integrated framework for fostering human factor sustainability and increased safety in aviation ramp operations. J. Aviat. Technol. Eng. 2015, 5, 44-52. [CrossRef]

2. Xiong, C.; Beckmann, V.; Tan, R. Effects of infrastructure on land use and land cover change (LUCC): The case of Hangzhou International Airport China. Sustainability 2018, 10, 2013. [CrossRef]

3. Occupational Safety and Health Act, Korean Law. No.17187 2020.09.08. Available online: https://elaw.klri.re.kr/eng_service/ lawView.do?hseq=43289\&lang=ENG (accessed on 15 April 2021).

4. Seoul economy, April 8, 2021. Available online: https:/ / www.sedaily.com/NewsView/22L06J6IIF (accessed on 15 April 2021).

5. Fu, G.; Xie, X.; Jia, Q.; Li, Z.; Chen, P.; Ge, Y. The development history of accident causation models in the past 100 years: $24 \mathrm{Model}$ a more modern accident causation model. Process Saf. Environ. Prot. 2020, 134, 47-48. [CrossRef]

6. Robertson, L.S. Injury Epidemiology, 4th ed.; Lulu Books: Morrisville, NC, USA, 2015.

7. ISO, I. 2009a. 31000. Risk Management-Principles and Guidelines; International Organization for Standardization: Geneva, Switzerland, 2009. 
8. Heinrich, H.W.; Petersen, D.; Roos, N. Industrial Accident Prevention; McGraw-Hill: New York, NY, USA, 1980.

9. Abdelhamid, T.S.; John, G.E. Identifying root causes of construction accidents. J. Constr. Eng. Manag. 2000, 126, 52-60. [CrossRef]

10. Heinrich, H.W.; Petersen, D.; Roos, N. Industrial Accident Prevention; McGraw-Hill: New York, NY, USA, 1950.

11. Dan, P. Techniques of Safety Management by Dan Petersen; Mcgraw-Hill Companies: New York, NY, USA, 1971.

12. Weaver, D.A. Management Index of Safety Performance. ASSE J. 1971, 5.

13. Bird, F.E.; Loftus, R.G. (Eds.) Loss Control Management; Institute Press, Division of International Loss Control Institute: Loganville, GA, USA, 1976.

14. Wiegman, D.; Shappell, S. A Huan Error Approach to Aviation Accident Analysis: The Human Factors Analysis and Classification, System, Ashgate; Routledge: London, UK, 2003; pp. 50-71.

15. Wang, J.; Zou, P.X.W.; Li, P.P. Critical factors and paths influencing construction workers' safety Risk tolerances. Accid. Anal. Prev. 2016, 93, 267-279. [CrossRef] [PubMed]

16. Banus, K.L.; Low, S.S.M.; Alan, H.S.C.; Saad, A. Construction Worker Risk-Taking Behavior Model with Individual and Organization Factors. Int. J. Environ. Res. Public Health 16 2019, 16, 1335.

17. Eagly, A.H.; Chaiken, S. The advantages of an inclusive definition of attitude. Soc. Cogn. 2007, 25, 582-602. [CrossRef]

18. Lee, S.C. Traffic Psychology; Hakjisa: Seoul, Korea, 2000.

19. Pennings, J.; Smidts, M.E. Assessing the construct validity of risk attitude. Manag. Sci. 2000, 46, 1337-1348. [CrossRef]

20. Starkey, N.J.; Isler, R.B. The role of executive function, personality and attitudes to risks in explaining self-reported driving behaviour in adolescent and adult male drivers. Transp. Res. Part F Trac. Psychol. Behav. 2016, 38, 127-136. [CrossRef]

21. Slovic, P.; Fischho, B.; Lichtenstein, S. Why study Risk perception? Risk Anal. 1982, 2, 83-93. [CrossRef]

22. ISO (International Organization for Standardization). ISO 31000:2009_Risk Management: Principles and Guidelines; Standards Australia: Sydney, Australia, 2009.

23. Kim, J.W.; Lee, H.S.; Park, M.S.; Kwon, N.H. A System Dynamics Approach for Modeling Cognitive Process of Construction Workers' Unsafe behavior, Korean. J. Constr. Eng. Manag. 2017, 18, 38-48.

24. Chengting, J.; Ming, J.; Jijun, L.; Xuqun, Y. Narcissistic personality and Risk perception among Chinese aviators: The mediating role of promotion focus. Int. J. Psychol. 2017, 52, 1-8.

25. Hunter, D.R. Risk perception and Risk tolerance in Aircraft Pilots, DTIC Document; Federal Aviation Administration: Washington, DC, USA, 2002.

26. Available online: https://www.magidglove.com/safety-matters/safety-risk-tolerance.aspx (accessed on 20 February 2021).

27. Simon, M.; Houghton, S.M.; Aquino, K. Cognitive Biases. Risk perception and venture formation: How individuals decide to start companies. J. Bus. Ventur. 2000, 15, 113-134. [CrossRef]

28. Montibeller, G.; VonWinterfeldt, D. Cognitive and motivational biases in decision and risk analysis. Risk Anal. 2015, 35, 1230-1251. [CrossRef] [PubMed]

29. Lichtenstein, S.; Slovic, P.; Fischhoff, B.; Layman, M.; Combs, B. Judged frequency of lethal events. J. Exp. Psychol. Hum. Learn. 1978, 4, 551. [CrossRef]

30. Irwin, C.E., Jr. Adolescence and Risk Taking: How Are They Related; Sage Publications Inc.: London, UK, 1993.

31. Kemp, R.V. Risk tolerance and safety management. Reliab. Eng. Syst. Saf. 1991, 31, 345-353. [CrossRef]

32. Jonah, B.A. Accident risk and risk-taking behavior among young drivers. Accid. Anal. Prev. 1986, 18, 265. [CrossRef]

33. Mitropoulos, P.; Abdelhamid, T.S.; Howell, G.A. Systems model of construction accident causation. J. Constr. Eng. Manag. 2005, 131, 816-825. [CrossRef]

34. Fang, M.Z.D. Cognitive causes of construction worker's Unsafe behavior and management measures. China Civ. Eng. J. 2012, 45, 45-49.

35. Li, H.J.; Liu, T.Z.; Li, Z.X. Study on theory framework of safety management capability in coal mine. J. Saf. Sci. Tech. 2010, 16, 143-148.

36. Choudhry, R.M.; Fang, D. Why operatives engage in unsafe work behavior: Investigating factors on construction sites. Saf. Sci. 2008, 46, 566-584. [CrossRef]

37. Dong-Chul, S. An explicative model of unsafe work behavior. Saf. Sci. 2005, 43, 187-211.

38. Yingyu, Z.; Yingjun, X. Analysis 320 coal mine accidents using structural equation modeling with unsafe conditions of the rules and regulations as exogenous variables. Accid. Anal. Prev. 2016, 92, 189-201.

39. Rowlinson, S. Hong Kong Construction: Safety Management and Law, 2nd ed.; Sweet and Maxwell Asia: Hong Kong, 2003.

40. Tam, C.; Zeng, S.; Deng, Z. Identifying elements of poor construction safety management in China. Saf. Sci. 2004, 42, 569-586. [CrossRef]

41. Ng, S.T.; Cheng, K.P.; Skitmore, R.M. A framework for evaluating the Safety performance of construction contractors. Build. Environ. 2005, 40, 1347-1355.

42. Aksorn, T.; Bonaventura, H.; Hadikusumo, W. Critical success factors influencing safety program performance in Thai construction projects. Saf. Sci. 2008, 46, 709-727. [CrossRef]

43. Nicole, S.N.; Yiu, D.; Chan, W.M.; Sze, N.N.; Ming, S.; Albert, P.C.C. Implementation of Safety Management System for Improving Construction Safety performance: A Structural Equation Modelling Approach. Buildings 2019, 1, 4-6.

44. Fogarty, G.J.; Shaw, A. Safety Climate and the Theory of Planned Behavior:Towards the prediction of Unsafe behavior. Accid. Anal. Prev. 2010, 42, 1457. [CrossRef] 
45. Hilde, S.; Helle, A.; Sigurd, W.; Jarle, E. Effects of leadership style and psychological job demands on situation awareness and the willingness to take a risk: A survey of selected offshore vessels. Saf. Sci. 2017, 93, 181.

46. Iraj, M.; Fakhradin, G. Constructing a Bayesian network model for improving safety behavior of employees at work places, Applied ergonomics. Appl. Ergon. 2017, 58, 35-47.

47. Tuqiang, Z.; Junyi, Z.; Dashzeveg, B. A Hybrid HFACS-BN Model for Analysis of Mongolian Aviation Professionals‘ Awareness of Human Factors Related to Aviation Safety. Sustainability 2018, 4, 8-11.

48. Song, J.J. The Method of SPSS/AMOS Statistic Analysis to Make Theses; 21Segisa: Gyeonggi-do, Korea, 2015.

49. Fornell, C.; Larcker, D.F. Evaluating Structural Equation Models with Unobservable Variables and Measurement Error. J. Mark. Res. 1981, 18, 39-50. [CrossRef]

50. Anderson, J.; Gerling, D.W. Structural Equation Modeling in Practice: A review and recommanded two-step approach. Psychol. Bull. 1988, 103, 411-423. [CrossRef] 